\title{
Uncovering Recovery: The Resistible Rise of Recovery and Resilience
}

\author{
DAVID HARPER \\ School of Psychology, University of East London, United Kingdom \\ EWEN SPEED \\ School of Health and Human Sciences. University of Essex, United Kingdom
}

\begin{abstract}
Discourses of recovery and resilience have risen to positions of dominance in the mental health field. Models of recovery and resilience enjoy purchase, in both policy and practice, across a range of settings from self-described psychiatric survivors to mental health charities through to statutory mental health service providers. Despite this ubiquity, there is confusion about what recovery means. In this article we problematize notions of recovery and resilience, and consider what, if anything, should be recovered from these concepts. We focus on three key issues, i) individualization, ii) the persistence of a deficit model, and iii) collective approaches to recovery. Through documentary analysis we consider these issues across third sector organizations, and public and mental health policy.

Firstly, definitional debates about recovery reflect wider ideological debates about the nature of mental health. The vagueness of these concepts and implicit assumptions inherent in dominant recovery and resilience discourses render them problematic because they individualize what are social problems. Secondly, these discourses, despite being seen as inherently liberatory are conceptually dependent on a notion of deficit in that talk of "positives" and "strengths" requires the existence of "negatives" and "weaknesses" for these concepts to make sense. We argue that this does little to substantially transform dominant understandings of psychological distress. Thirdly, these issues combine to impact upon the progressive potential of recovery. It comes to be seen as an individualistic experiential narrative accompaniment to medical understandings where the structural causes of distress are obscured. This in turn impacts upon the potential for recovery to be used to explore more collective and political aspects of emotional distress.

Drawing on the work of Fraser, we use this critique to characterize "recovery" as a "struggle for recognition," founded on a model of identity politics which displaces and marginalizes the need for social, political and economic redistribution to address many of the underlying causes of emotional distress. We conclude by stating that it is only when the collective, structural experiences of inequality and injustice are explicitly linked to processes of emotional distress that recovery will be possible.
\end{abstract}




\section{Introduction}

People who experience psychological distress also experience social injustice. This injustice impacts upon their social, economic and political lives. For example, the social patterning of distress reflects broader social inequalities (Mirowsky \& Ross, 2003) as does people's experience of mental health services (Pilgrim, 2009; Rogers \& Pilgrim, 2003). Furthermore, the acquisition of psychiatric diagnoses may also present barriers to full time employment, or create barriers to housing (Social Exclusion Unit, 2004). These barriers to full social, political and economic participation can be characterized as a problem of redistributive justice (Fraser, 2000). Mental health service users and survivors also experience devalued identities through the acquisition of psychiatric diagnoses. Fraser (2000) identifies this as a problem of recognition, whereby a normatively framed negative aspect of identity stigmatizes a particular group. One of the sources of such devaluation is the way in which psychiatric terminology is deficit-laden and pathologizing (Gergen, 1990). However, in recent years, the popular and professional literature has become increasingly dominated by concepts that appear to reject a deficit-based approach. In this article we focus on two of these concepts in more detail: recovery and resilience. We consider the possibilities these concepts offer people in the mental health field, in particular, in terms of struggles around the politics of recognition and redistribution. We provide a perspective from the UK, where the recovery approach has been gradually appearing in mental health policy over the last decade (Perkins \& Slade, 2012).

That the notion of recovery has moved from being a marginal to a central concern in mental health services in the UK (Pilgrim, 2008), North America (Anthony, 1991, 1993), Australia and New Zealand (Australian Health Ministers, 2003; O’Hagan, 2001; Ramon, Healy, \& Renouf, 2007) and elsewhere in a relatively short amount of time is striking. Although proponents argue that the focus on recovery and resilience is a uniformly positive development, in this article we problematize this stance. As with many taken-for-granted concepts, there are a number of unintended consequences that flow from their use in a policy context-consequences that may not be obvious to many survivors and professionals and which may even be inconsistent with the stated aims of authors. Moreover, these developments have tended to be framed within a broad framework informed by identity politics. This has significant implications for issues of social and distributive justice in terms of mental health service users and survivors.

In this paper, we will critique three aspects of discourse related to recovery and resilience as they are utilized in policy frameworks. Firstly, we argue that these concepts are individualistic, based on medicalized and neoliberal notions of individual responsibility. This individualism is commensurate with the rise of neoliberal identity politics, focused on individualizing disparate group struggles of recognition rather than collective struggles around redistribution. Secondly, we contend that, rather than banishing deficit, recovery and resilience discourse simply reframes deficits as strengths and 
is thus implicitly reliant on deficit-based models. This failure to challenge the underlying deficit inherent in contemporary notions of recovery results in a situation whereby recovery can be seen to present barriers to social and political participation. In turn this can be seen as extending (rather than limiting) the stigmatization of the identified group (i.e. perpetuating their status subordination, see Fraser, 2000, 2005, 2007). Finally, we note how important structural factors (health and social inequalities) are de-emphasized and backgrounded within a neoliberally informed framework of identity politics.

These three aspects of recovery and resilience obstruct rather than facilitate efforts to improve the situations of mental health service users/survivors, obscuring the social and political links between distress and structural injustice. Moreover, the focus on the individual means that the collective responses to injustice seen in the activities of the broader Survivor Movement are downplayed. Finally, the failure to escape deficit-laden discourse means that there is a restricted conceptual repertoire available to problematize these inadequacies.

The paper includes both a documentary and conceptual analysis of these notions, focusing primarily on recovery (since this concept is founded on an assumption of resilience). First we define the concepts.

\section{Defining Resilience and Recovery}

\section{The Nature of Resilience}

Resilience refers to an ability to respond to and cope with adversity. Evidence to support the notion of resilience as an aspect of mental health includes a consistent research finding that rates of mental distress vary between people from apparently similar backgrounds. Similarly, Goldberg and Huxley, (1992) discuss the notion of spontaneous restitution whereby a proportion of people experiencing mental distress spontaneously improve without external intervention. Resilience was promoted by the humanistic psychotherapies in the 1940s and 1950s, and the human potential movement of the 1960s promulgated the notion of self-healing human beings. In terms of the historical development of "resilience," these approaches combined with libertarian professional movements (such as the 1970s radical non-interventionist social work). By the late 1980s there was a move towards solution-focused therapy (de Shazer, 1988) and, within mainstream psychology, towards positive psychology (Seligman, 1998). This entailed creating a research paradigm where the emphasis was on psychological processes that were deemed to be protective or ameliorating rather than those which were deemed to focus on deficits. It is in these broad therapeutic contexts that the problematic notions of resilience and recovery developed.

One important distinction to be made is between the term recovery and the notion of recovery. Many commentators conflate the two, which can 
lead to confusion. Thus Chamberlin's groundbreaking On our own (1978) is sometimes credited as part of the history of the recovery movement. However, the actual term recovery only appears twice in the whole book, both times mentioned only in passing.

As Davidson, O’Connell, Tondora, Lawless, \& Evans (2005) note "the only thing about which most stakeholders seem to be able to agree, in fact, is that the notion of recovery has become the focus of a considerable amount of confusion and debate between and among various constituencies within the mental health community" (p. 480). The origins of the recovery model in mental health lie in the work of William Anthony (1991, 1993). Broadly speaking, it is a highly individualized and experiential concept, which proposes a framework for recovery from "mental illness," based on individual changes to attitudes, behaviours and beliefs by the psychiatric patient. Anthony notes that the work of survivors like Deegan (see Deegan, 1998) was one of the inspirations for this approach and Deegan does, indeed use both the concept and the term recovery.

In the context of this paper, it is worthy of note that survivor groups tend to place more emphasis on the work of Deegan and other survivors, in their use of recovery. Pilgrim (2008) delineates three competing versions of the recovery approach: a biomedical version focused solely on an improvement in symptomatology; a more socially-oriented model, in the tradition of psychiatric rehabilitation, focused on improvements in symptoms and quality of life; and a psychiatric survivor movement approach focused on liberation rather than cure. For example, for those survivors who popularize notions of recovery-like Deegan (1998) - their main concern is, arguably, to critique the narrow limits of traditional notions of rehabilitation and with developing narratives of hope, rather than delineating a model per se. Moreover, some survivors see the notion of recovery as the antithesis of a reductive professional-led model. Coleman (1999) explicitly advocates a political notion of recovery, contrasting it against a psychiatric conceptualization. Dillon (2011) also outlines a political and collective approach to recovery, contrasting it with a biomedical approach, arguing that "improving all of our personal experiences means that we must collectively address oppressive political structures. This for me is why the personal is political" (2011, p. 157). We return to this issue later.

Within the literature, Anthony's is not the only model (see, for example, Jacobson \& Greenley, 2001). In their review of recovery models Leamy, Bird, Le Boutillier, Williams, \& Slade (2011) examined 97 separate contributions. In addition, there have been attempts to clarify, through qualitative research with service users/survivors, key elements in accounts of recovery from distress (Adame \& Hornstein, 2006; Adame \& Knudson, 2008; Cohen, 2005; Ochocka, Nelson, \& Janzen, 2005; Young \& Ensing, 1999). This range of competing versions means that specific concepts of recovery are often vague. We present some analysis of policy documents to offer some empirical grounding to the ways in which recovery is being used in a practical context. We identify three key problems. 


\section{Three Problematic Aspects of Recovery and Resilience Discourse}

We now proceed by demonstrating the three elements of this critique through documentary analysis, before relating this analysis to wider concerns around social justice.

\section{Individualization}

No health without mental health (Department of Health, 2011) is a UK "crossgovernment mental health outcomes strategy" intended to establish parity of treatment between services for people with mental and those with physical health problems. In one sense, it can be regarded as an attempt to redress some of the status subordination experienced by mental health service users. It is selected for analysis here because it offers a governmental narrative of how recovery is defined and operationalized in a policy context.

Recovery is explicitly defined in section two of the strategy, under the heading of "Guiding Values and Principles." These are listed as "freedom, fairness, and responsibility," (2011, p. 16). The definition of recovery is listed under the first of these values (freedom). Within this definition, recovery is outlined through reference to a detailed footnote that describes recovery as follows:

The term "recovery" has developed a specific meaning in mental health. It has been defined as: "A deeply personal, unique process of changing one's attitudes, values, feelings, goals, skills and/or roles. It is a way of living a satisfying, hopeful and contributing life, even with limitations caused by the illness. Recovery involves the development of new meaning and purpose in one's life" (Anthony, 1993) . . . Although the term is not used in relation to children and young people, the underlying principles of the recovery approach are equally applicable.

This quote from Anthony offers the most frequently used interpretation of what recovery is, and how it relates to a person's mental health. The onus for recovery is on the individual, whereby that individual must change their attitudes, values, feelings, goals, skills and roles, in a deeply personal way, in order to effect change within their own life. Rather than effecting social change, the marginalized other is required to change their personal outlook. By failing to problematize the medical model, Anthony's model requires that the person accept that they have an illness (i.e. that they endorse the medical model). Recovery is thus framed as the need for the service user to acknowledge the inappropriateness of their negative beliefs, values and behaviours and to rethink these "inappropriate" cognitions and behaviours into a set of more satisfying, hopeful and contributory values and behaviours. This model of recovery makes emotional distress an explicit problem of individualized identity, rather than for example, an effect of structural inequality. 
The individualized personal nature of recovery is a central theme across another UK policy document, this time from Rethink, a leading UK mental health membership charity. The document is entitled 100 ways to support Recovery (Slade, 2009). Like the cross government strategy this document draws from the work of Anthony to provide a framework for recovery but adds a distinction between "personal recovery" (seen as within the domain of the "expertise of people with lived experience of mental illness") and "clinical recovery" (seen as within the domain of the "expertise of mental health professionals"). Clinical recovery is concerned with the eradication of symptoms, the restoration of "social functioning" and other ways of "getting back to normal," (p. 4). This distinction functions to effectively locate "personal recovery" as an adjunct to clinical recovery, and this complementarity avoids recovery being seen as inherently contested.

The document outlines four "Personal Recovery Tasks" (p. 4). These are listed as:

i) developing a positive identity;

ii) framing the "mental illness";

iii) self-managing the mental illness; and,

iv) developing valued social roles.

We focus on the third task, which illustrates an important aspect of an individualistic approach to recovery: responsibilization. Neoliberal policies invite people to see certain problems as the responsibility of the individual rather than, for example, the State. As a result, taking personal responsibility (through self-management) of the "mental illness experience" (p. 4) entails, as Lemke argues "shifting the responsibility for social risks such as illness, unemployment, poverty, etc., and for life in society into the domain for which the individual is responsible and transforming it into a problem of "self-care"" (Lemke, 2001, p. 201). For example, the document states, "framing the mental illness experience provides a context in which it becomes one of life's challenges, allowing the ability to self-manage to develop. The transition is from being clinically managed to taking personal responsibility through self-management," (p. 4). This program of self-care, Lemke argues, is tightly aligned with neoliberal forms of government, which "characteristically develop indirect techniques for leading and controlling individuals without at the same time being responsible for them," (p. 201). An example of this can be seen in the document where it notes that self-care "does not mean doing everything on your own. It means being responsible for your own well-being, including seeking help and support from others when necessary” (p. 4).

Elsewhere in the document there is a direct comparison between traditional approaches and recovery approaches. Under a section entitled "Goals of the Service" (p. 6) traditional approaches are defined as "anti-disease" whereas recovery approaches are defined as "pro-health." Similarly, "compliance" is contrasted with "choice," and a traditional "return to normal" is contrasted with a recovered "transformation." This demonstrates a clear attempt to 
"positivize" recovery-oriented services. Self-management and patient choice are key elements of neoliberal health policy. These ascriptions are of a piece with other ideological processes that seek to define service users as responsibilized consumers. This idea is further iterated in the fourth criterion. Previously traditional services sought a return to normal, whereas, recovery services, we are told, seek transformation. This transformation is construed in terms of the individual service user, not in terms of the wider structural conditions of inequality. This obviously has implications for the shape of policy initiatives to reduce mental health service users and survivors experience of social injustice. The championing of practices of choice, selfcontrol and personal transformation are compatible with neoliberal forms of healthcare provision intended to produce responsibilized individualized service users. One way in which this has been manifested in traditional service approaches has been in linking distress with internal deficits and recovery with internal strengths. It is to the centrality of the notion of deficit that we turn next.

\section{The Persistence of Deficit}

The second element of our critique is that recovery and resilience discourse continues to be implicitly reliant on a model of deficit. Consider again the 2011 strategy document, No health without mental health.

The strategy is organized around six key strategy goals. Each goal has an accompanying explanation that identifies specific examples of the overall goal. Limitations of space mean we can only focus on one goal here: "more people with mental health problems will recover." The accompanying explanation identifies seven indicative examples:

More people who develop mental health problems will have a good quality of life - greater ability to manage their own lives, stronger social relationships, a greater sense of purpose, the skills they need for living and working, improved chances in education, better employment rates and a suitable and stable place to live. (p. 6)

This extract contains a number of features that clearly imply a particular underlying aetiology of emotional distress. Implicit in this model is an assertion that people who develop mental health problems have a poor quality of life, are unable to manage their own lives, lack strong social relationships, have a lesser sense of purpose, lack necessary skills for living and working, have lesser opportunities for education, employment and poorer access to secure housing. All of these characteristics are predicated on existing negatives (deficits) being reframed as potential positives.

A deficit model persists in that, although framed in positive terms, each positive term is dependent for its meaning on the opposite negative term. Billig, et al. (1988) note how this is a common feature of thinking and talking. A focus on strengths does not do away with the notion that there are 
deficits; indeed they are predicated upon an underlying and enduring deficit model. This model is normative, accentuating the positive aspects of deficits, rather than challenging the ontology of the deficit model. As such, it reifies difference and sustains the subordinated status of mental health service users.

This approach to recovery does not offer an alternative means of understanding the nature of emotional distress; it simply reframes existing understandings of mental illness. This is problematic when the point of origin of much recovery work was about challenging existing notions of mental health and proposing alternative notions of emotional distress. Next, we focus on the third element of our critique, the backgrounding of structural injustice and collective responses to it.

\section{De-Emphasizing Structural Causes of, and Collective Responses to, Distress}

Earlier, we identified four "Personal Recovery Tasks" (p. 4) in 100 ways to support recovery (Slade, 2009), the fourth of which was "developing valued social roles." A clear emphasis in this fourth criterion is put on relationships with others and the support that this might bring: "working with the person in their social context is vital, especially during times of crisis when support usually received from friends, family and colleagues can become most strained" (p. 4). Crucially, the social context is defined in terms of what it might add to the interpersonal context. This reduction of the meaning of "social" to the "interpersonal" prioritizes a very narrow view of the social (predicated on personal interaction), and limits the potential for consideration of issues of social injustice within such a narrow context.

This is not to say that inequality is ignored in discussions of recovery. For example, Jacobson and Greenley's (2001) model of recovery includes a concern with empowerment but this is framed as "a sense of empowerment" (p. 483), a psychologized and individualized reading of empowerment, rather than an actual redistribution of power. Thus, inequality is not ignored but it is addressed in a narrow individualized form. This prioritizing allows for a backgrounding of many of the key issues of social inequality that are known to contribute to poor mental health (such as the community-wide impacts of living in areas of poverty, see Dorling, 2011). The Rethink document appears to accept a priori that social inequality will be present, but places the onus on the service user to rearticulate the effects of social inequality in terms of their individualized, responsibilized self. This is redolent of the spoiled identity of the service user implicitly evoked by Anthony, (1993). This model (directly or indirectly) has the effect of minimizing the role and import of social inequality in population level rates of emotional distress. It functions to make mental illness an individual problem with personal solutions. This model draws from an individualized rights-based form of identity politics, which, as the Social Perspective Network argues, does "not focus enough on the need for society to change as well," (Slade, 2009, p. 56). 
For White (2004) these kind of accounts obscure context - the opportunities or material conditions which facilitate people getting through adversity. Smail has made a similar point - that the extent to which people can make changes in their lives will depend on their access to powers and resources (e.g. educational, physical, social, political and suchlike). Although, he argues, these originate in the external material environment "possession of or access to such powers will often appear superficially as personal characteristics or qualities" (1990, p. 8). These manifestations of responsible individuals speak directly to neoliberal models of the service user.

In our analysis of these documents we have seen a number of recurring themes. The focus on individual journeys, whilst to some degree welcome, also leads to practices of atomization (where social processes are reduced to individual elements), individualization and responsibilization. Moreover, the dominance of medical understandings of emotional distress is perpetuated, since the recovery model does not challenge them. The recovery model does not erase the notion of deficit; more accurately it reframes it, limiting the potential for developing truly alternative models and understanding of the nature of emotional distress. Finally, social inequality, whilst acknowledged, is backgrounded and there is a tension between the personal and political in that recovery is seen as an individual and personal practice, which simultaneously downplays the role of collective and political aspects of distress.

\section{Individualization, Deficit, Inequality and Social Justice}

Our argument here is not that the personal should be secondary to the political, more that an awareness of the need for balance between the personal and political needs to be acknowledged by practitioners and service users. There is a need to rebalance the tension between the politics of recognition and the politics of redistribution such that they complement rather than contradict each other.

To do this, we utilize Fraser's framework founded on notions of status (rather than identity) as a means of contextualizing and explaining the implications of recovery-based individualization, deficit and inequality in relation to questions of social justice (see Fraser, 1995, 2000, 2005, 2007). We consider how these three factors combine to marginalize consideration of more macro level contributors to emotional distress, such as conditions of economic inequality (Fraser describes this marginalization as a "problem of displacement"). Also, we consider how a focus on identity underscores rather than disavows differences between the pathologized "other" and the normative "mainstream" (Fraser describes this as a "problem of reification"). We accomplish this through a consideration of processes of power and domination in the mental health field, particularly in terms of the continuing dominance or hegemony of biomedical approaches. 


\section{Recovery and Hegemony}

We have argued that dominant norms of medicine and indeed government are embedded in, and perpetuated by, the mainstream recovery model. Consequently, it offers survivors little in the way of alternatives to the present medical and politically dominant ways of making sense of emotional distress. The recovery model clearly engages with an "identity model" of recognition. This model characterizes any negative judgment of a social group as a problem of "misrecognition," whereby the majority regards an element of the groups' identity as negative. The task within this frame (for members of the minority group) becomes one of making the negative trait positive, such that the misrecognition might be redressed. The solution to this misrecognition is that members of minority groups

...reject such images in favor of new self-representations of their own making, jettisoning internalized, negative identifies and joining collectively to produce a self-affirming culture of their own - which publicly asserted will gain the respect and esteem of society at large. (Fraser, 2000, p. 110)

The recovery model clearly fits into this political project. The question it begs is where the critique of social inequality, or medical power might fit in these self-affirmed representations. The recovery model directs attention to the positive group identity whilst simultaneously failing to problematize the conditions (beyond the group) that contributed to the situation; it is blind to the wider social and political struggle. It also displaces the political nature of the struggle between different power elites and the psychiatric patient that were such a central feature to the history of the psychiatric survivor movement. Notions of equivalence and difference allow us to bring consideration of this political struggle back into the discussion.

\section{Equivalence and Difference}

Laclau and Mouffe (1985) assert that political struggles can be characterized in terms of "logics of equivalence" or "logics of difference." The former relate to those struggles where the differences between groups are downplayed to create a united front against a common enemy, whereas the latter relate to struggles where differences are accentuated. An example of equivalence would be a social movement against psychiatry, where differences of class, gender, ethnicity etc. would be backgrounded (but not denied) and similarities between groups would be accentuated (thus creating a collective banner behind which to mobilize - e.g. as psychiatric survivors). However, this dynamic is problematic. The logic of equivalence must seek to build a broad based movement against a hegemonic power, in a dynamic context that acknowledges and embraces difference rather than reifying the collective identity; Fraser describes this as an "affirmative recognition of difference" (2000, p. 116), perhaps characterized as a broad coalition. If the movement 
does not recognize this difference then the collective equivalence between actors risks becoming atrophied. Fraser (2000) touches upon this dynamic when she discusses the reification of identity politics. For Fraser, there is a tendency for equivalences to become a singular, simplified group identity. The promotion of recovery, within the mainstream, as a user-led process for dealing with emotional distress, lends recovery discourse an authenticity that it does not command and imposes a singular "simplified group identity which denies the complexity of people's lives," (Fraser, 2000, p. 112). This singular identity (e.g. as recovering service users) does not pay sufficient attention to other ongoing political struggles across different groups of actors, such as the dominance of psychiatric pathology or economic inequalities and the impact these factors have in perpetuating emotional distress.

Relatedly, logics of difference are those strategies intended to amplify dissimilarities between and within groups. This logic seeks to break down chains of equivalences and to foster differences in order to maintain a position of dominance in the field. Consider again the problems of misrecognition. Identifying specific groups as deficient or inferior locates them within "institutionalized relations of social subordination" (Fraser, 2000). Institutionalized subordination limits opportunities for participatory parity, and therefore marks a clear case of social injustice. Somewhat paradoxically, the recovery "model" could be argued to be seeking to redress this disparity, by rearticulating this "deficit" within a normative "strengths" framework. However, it fails in this regard; by seeking parity through a valorized individualized identity, whilst ignoring the need for institutional social change. The focus on a "recovered" identity supports dominant norms, and constructs an "unrecovered identity" as intrinsically negative. It ignores the need for transformations of "institutionalized value patterns" (Fraser, 2000), that themselves block opportunities for participatory parity. In this context, the focus on individual change alone is always doomed to failure in a social justice context. The collective survivor movement offers an alternative focus for progressive politics.

\section{The Survivor Movement as a Social Justice Movement}

Historically, the survivor movement represented an attempt to transform medical dominance. It sought to offer a counter-hegemonic strategy, based on non-medical understandings of emotional distress, informed by social justice and equality. In this sense, it sought to create a logic of equivalence. We do not intend to homogenize the survivor movement; like any other movement, it comprises cross-cutting currents of thought and action but, we would argue, a dispassionate observer of the movement in the 1970s and 1980s would not have said that its main concern was recovery per se. Rather, the main demands of the movement were to call for the ending of coercive practices and the development of "patient-controlled alternatives." Part of this project involved developing a focus on the survivor's individual experience as a 
counter to the totalizing, pathologizing discourse of medicine. This resistance against universalistic medicine built on the 1960s counter culture (such as assertions that the personal is political, see Hanisch, 1970), the women's movement and other civil rights campaigns and the anti-psychiatry legacy (such as Laing's 1967 work on the politics of experience).

In this contemporary context we suggest that the experiential, personal biography element of the survivor movement has been co-opted by mainstream politics and medicine, and that the radical redistributive element has been marginalized and displaced. Within this co-opted model, recovery is concerned with inward transformation as a solution to individual problems, whilst the social and political context is backgrounded or ignored. By extension, these accounts also privilege professional-led interventions to help recovery. This is problematic as survivors' accounts show that their journeys are extremely diverse with professional involvement playing a part only in some narratives (e.g. Adame \& Hornstein, 2006; Adame \& Knudson, 2008; Cohen, 2005; Ochocka, Clare \& May, 2005; Young \& Ensing, 1999) whilst many survivors report "experiencing recovery" only after freeing themselves from professional intervention (Thornhill, et al., 2004). That the recovery movement has not, for example, led to any serious challenge to the medicalization of distress is further evidence of this co-option.

The focus on individual, rather than collective, experience functions to accentuate differences between survivors and indeed organizations. By focusing on individuals the role and potential of collective approaches is obscured. By co-opting recovery, and focusing on individuals, there is clearly a neglect of the social and material context of emotional distress and, in neglecting the impress of power, there is a tendency to voluntarism - the idea that people can simply change through force of will despite countervailing structural factors (Smail, 2004). Similarly, many of the real demands of the survivor movement have been obscured. As Trivedi (2010) notes, what does the recovery approach have to say about professional power? One of the striking things about the survivors movement has been just that - it is a collective social movement (Crossley, 2005; Speed, 2006). Harper (2010) notes the 24 demands made by the Mental Patients Union (MPU), set up in the UK in late 1972 following an occupation of the Paddington Day Hospital by patients and staff (Spandler, 2006). Only nine of these demands have been met, many only partially. The 15 outstanding demands include: the abolition of compulsory treatment and seclusion; the "abolition of irreversible psychiatric 'treatments' like ECT, psychosurgery and medication; and that 'all patients should have the right to have any 'treatment' which they believe will help them" (Roberts, 2008). Claims like these from the survivor movement can be regarded as attempts to mobilize a collective campaign, to identify those aspects of psychiatric practice that are political, or that speak to a common experience. Developing a campaign around these issues would enable service users to identify their collective similarity (or equivalence) rather than focusing on a politics of misrecognition. It would allow service users to draw attention to, and problematize, processes of, social injustice, 
economic, political and social inequality that are so prevalent in the incidence of emotional distress.

There is clearly a need to return to the some of the key demands of the survivor movement and to consider how to maintain an explicitly transformative agenda in mental health research, policy and practice.

\section{Beyond Recovery and Resilience: Alternative Conceptualizations}

Given the problems with recovery and resilience discourse what are we to do? Can it be reclaimed and used differently in order to achieve greater social justice for those in distress? Or, is it so inherently limited that we need to move beyond it and use an entirely different vocabulary?

There are a number of things in favor of the first approach. Firstly, the term recovery is in wide use in the general population. Secondly, the recovery model is widely known and may provide a vehicle for addressing issues of injustice and making certain demands, for example that services reorganize so they are consistent with political notions of recovery.

However, there are also things in favor of the second approach. For example, whilst the term recovery is in wide use, many understand it as a medical term, implying recovery from an illness or disease (Wallcraft, 2005). Although there are other non-medical definitions of recovery, the issue is that the term itself has an ambiguous meaning. Because of this, on what basis can we say that a mental health service is or is not "recovery-oriented"? How do we deal with conflicts between models (e.g. clinical recovery versus personal recovery)? Does it simply become a case of arguing for one's own definition of recovery: "this is what recovery really means ..." or "this is what recovery means for me"?

Rather than seeking a consensus view of what recovery is, it is, perhaps, more useful to think about the ways in which some of the underlying principles of the survivor movement might lead to a re-invigorated debate about how the personal can be made political, such that struggles of recognition can complement struggles of redistribution, to effect progressive social change. Moreover, if we are to try to move beyond recovery and resilience discourse, it is important to consider ways of holding on to elements that are likely to be helpful in leading to more socially just outcomes.

In proposing a way forward, it is necessary to identify an approach that combines the progressive elements of a politics of recognition with a struggle for redistribution. In a mental health context, redistribution would involve engaging with the social, political and economic processes that created processes of status subordination for service users, across all aspects of social, political and economic participation. Fraser (2000) proposes a solution that rejects the identity mode of misrecognition and instead argues for a politics of status. This alternative neither reifies subordinated identity nor does it displace struggles for redistribution. Instead it seeks to undermine notions of group specificity, arguing that it is not a misrecognized 
identity that is the endpoint of any political struggle, but rather the struggle should seek "institutional remedies for institutionalized harms" that are a consequence of misrecognition. A recovery model based on an implicit notion of deficit clearly does not accomplish this. But the recovery model is not alone in this regard. Fraser argues that any struggle that relies solely on issues of recognition will fail. Moves for redistributive justice must be coupled to issues of recognition. The economic impact of being identified as a psychiatric patient must be considered in conjunction with the social and political impacts of this identification. It is only when redistribution and misrecognition are considered together that the extent of the social injustice can be gauged in line with the best means of addressing it, such that parity of participation can be considered.

\section{What should we recover from "recovery"?}

Firstly, the focus on the individual biographical narratives of survivors seems genuinely helpful, as does the notion of each individual going on a personal journey. Secondly, the optimism about the possibility of healing, of engaging in a process of change in a person's relationship to distress is to be welcomed. There is an assumption that all these elements exist because of the recovery approach or model but, in fact, they pre-existed the wide use of this term. Neither biographical journey narratives nor optimism necessarily entail the other conceptual and policy baggage that recovery and resilience bring with them as we have described. Indeed, the way these concepts have been implemented in services has led to a number of unintended consequences in that the "personal" has become disconnected from the "political." Thus, within the recovery and resilience literature there is little emphasis on the importance of survivors getting together and sharing experiences, even less, that they might seek to act on insights gained in this process. However, in the context of the women's movement, for example, this link between personal and collective understanding and action was key (Hanisch, 1970). It is necessary that the link between individual narratives and wider social, political and economic struggles are strengthened and maintained. Possible alternatives need to value individual narratives but place them in a collective context, developing explanatory accounts that are not located intra-psychically but rather, which are attentive to the structural conditions which might facilitate "coming through" adversity or "moving forward" (Ochocka, et al., 2005) and which also acknowledge the impact of social inequalities on aetiology and the ability to change in relation to distress.

In focusing on the power of individual survivor narratives it is important not to simply appropriate them so as to insert them into professionally derived conceptual frameworks. Instead more socially just frameworks are required, more fully grounded in everyday experience. These might include not only accounts of their distress but also problematic relationships with health services. Or address power disparities in relation to professionals and 
clashing viewpoints on the nature of that distress, or indeed broader issues of inequality around class, ethnicity, gender or sexuality. In understanding distress there is a need for more sophisticated understandings of experience (Trivedi, 2010), framed in people's own words, using the language that survivors themselves use (Wallcraft \& Michaelson, 2001). However, these narratives need to be understood in a collective and political and economic context. It is no surprise that some of the most inspiring personal accounts occur at survivor-run conferences like Intervoice's ${ }^{2}$ annual international hearing voices conference attended by equal numbers of survivors and professionals. At such events, the individual is not simply relating a biographical narrative, rather they are giving a public testimony, often intended to lead to changes in services - here, the personal is indistinguishable from the political. In this regard, Boyle (2003) suggests a focus on aetiology that examines the social and societal causes of distress. In her discussion of another individualized and psychologized concept — that of "vulnerability," Boyle suggests that one alternative is to focus on the external causes of things to which people are supposedly vulnerable:

Then, rather than simply naming the damage, we might gradually name the systems or people who do the damage, eventually making them the subject of our sentences ... [w] might also take up Paul Gilbert's recent suggestion (2002) and have a "Defeat abuse," rather than "Defeat depression" campaign. (2003, p. 30)

Such a focus might lead us to identify the structural facilitators of recovery (e.g. stable income, good housing, employment etc.). Another way of examining the social context is to look towards approaches that firmly locate the individual in their social and societal context. Hagan and Smail (1997a, 1997b) for example, introduce the notion of power-mapping. This is a process of identifying with a service user what access they have to a whole range of resources (e.g. personal, bodily, interpersonal, social, financial etc.). Burton and Kagan's (2008) societal case formulation provides another way of doing this. The aim in these kinds of approaches is a form of collective conscientization (Freire, 1974) where people come to understand the structural causes of their oppression. Smail talks of the related notion of "outsight" which he contrasts with what he terms "magical voluntarist" forms of therapeutic help - that is, approaches which are based on the assumption that, perhaps with the expert help of a therapist, a person is able to change the way they think about the world through sheer force of will, rather than attempt to change the world that causes them distress.

If the aim of magical voluntarist psychology is to achieve the kind of "insight" that allows the person to see the error of their ways and adjust their conduct accordingly, the aim of a social environmentalist psychology is more or less completely the opposite: to help the person achieve "outsight," such that the causes of distress can be demystified and the extent of their own responsibility for their condition put into its proper perspective. (Smail, 2005, p. 32) 


\section{Conclusion-Challenging the Binary?}

Our critique leads to two key conclusions. Firstly, there is a need for the implications and limitations of recovery and resilience discourse to be much more fully elaborated by different proponents. The one size fits all approach to recovery and resilience is not adequate nor is it appropriate in the context of a progressive politics of emotional distress aimed at greater social justice for those who experience it. Indeed, we would argue that positive psychology does little to move the debate on, as it continues to be constituted by the ghost of psychological deficits. Talking about strengths simply privileges the other side of the binary opposition of deficit-strength. We need, instead, to challenge this opposition. Secondly, one way of distinguishing different approaches to recovery and resilience is how they conceptualize the political (and the social and the economic) in the experience of emotional distress (both individually and collectively). We do not discount the need for recovery and resilience approaches to give a central importance to individual experience but it is absolutely vital that the conceptualization of individual experience is one that can be tied back to collective and structural experiences of distress, inequality and injustice.

\footnotetext{
Notes

1 Possible alternate meanings for the "illness" are offered in the context of "spiritual, cultural or existential crises." However, although other frameworks are alluded to, the lack of a sustained analysis of structural factors risks those identified factors being regarded primarily as lifestyle factors.

2 http://www.intervoiceonline.org/
}

\section{References}

Adame, A.L., \& Hornstein, G.A. (2006). Representing madness: How are subjective experiences of emotional distress presented in first-person accounts? The Humanistic Psychologist, 34, 135-158.

Adame, A.L., \& Knudson, R.M. (2008). Recovery and the good life: How psychiatric survivors are revisioning the healing process. Journal of Humanistic Psychology, 48, 142-164.

Anthony, W. A. (1991). Recovery from mental illness: The new vision of services researchers. Innovations and Research, 1, 13-14

Anthony, W. A. (1993). Recovery from mental illness: The guiding vision of the mental health system in the 1990s. Psychosocial Rehabilitation Journal, 16, 11-23

Australian Health Ministers (2003). National mental health plan 2003-2008. Canberra: Australian Government.

Billig, M., Condor, S., Edwards, D., Gane, M., Middleton, D., \& Radley, A. (1988). Ideological dilemmas: A social psychology of everyday thinking. London: Sage.

Boyle, M. (2003). The dangers of vulnerability. Clinical Psychology, 24, 27-30.

Burton, M., \& Kagan, C. (2008). Societal case formulation (expanded version). Retrieved from: http://www.compsy.org.uk/Societal $\% 20$ case $\% 20$ formulation $\% 20$ expanded $\% 20$ version $\% 20$ 2008.pdf

Chamberlin, J. (1978). On our own: Patient-controlled alternatives to the mental health system. New York, NY: McGraw-Hill 
Cohen, O. (2005). How do we recover? An analysis of psychiatric survivor oral histories. Journal of Humanistic Psychology, 45, 333-354.

Coleman, R. (1999). Recovery: An alien concept? Gloucester: Handsell Publishing.

Crossley, N. (2005). Contesting psychiatry: Social movements in mental health. London: Routledge.

Davidson, L., O’Connell, M.J., Tondora, J., Lawless, M., \& Evans, A.C. (2005). Recovery in serious mental illness: A new wine or just a new bottle? Professional Psychology: Research and Practice, 36, 480-487.

Deegan, P. E. (1998). Recovery: The lived experience of rehabilitation. Psychosocial Rehabilitation Journal, 11, 11-19

Department of Health. (2011). No health without mental health: A cross-government mental health outcomes strategy for people of all ages. London: HMSO

de Shazer, S. (1988). Clues: Investigating solutions in brief therapy. London: Norton.

Dillon, J. (2011). The personal is the political. In M. Rapley, J. Moncrieff \& J. Dillon (Eds.), De-medicalizing misery: Psychiatry, psychology and the human condition (pp. 141-157). Basingstoke: Palgrave MacMillan.

Dorling, D. (2011). Injustice: Why social inequality persists. Bristol: Policy Press

Fraser, N. (1995) From redistribution to recognition? Dilemmas of justice in a "post-socialist" age, New Left Review, I(July/August), 68-93.

Fraser, N. (2000) Rethinking recognition, New Left Review, 3, 107-120.

Fraser, N. (2005) Reframing justice in a globalizing world, New Left Review, 36, 69-88.

Fraser, N. (2007). Feminist politics in the age of recognition: A two-dimensional approach to gender justice. Studies in Social Justice, Volume 1, 23-35.

Freire, P. (1974). Pedagogy of the oppressed. Harmondsworth: Penguin.

Gergen, K.J. (1990). Therapeutic professions and the diffusion of deficit. The Journal of Mind and Behavior, 11, 353-368.

Gilbert, P. (2002) Understanding the biopsychosocial approach II: Individual and social interventions. Clinical Psychology, 15, 28-32

Goldberg, D. \& Huxley, P. (1992). Common mental disorders: A bio-social model. London: Routledge.

Hagan, T., \& Smail, D. (1997a). Power-mapping -- I. Background and basic methodology. Journal of Community \& Applied Social Psychology, 7, 257-267.

Hagan, T., \& Smail, D. (1997b). Power-mapping -- II. Practical application: The example of child sexual abuse. Journal of Community \& Applied Social Psychology, 7, 269-284.

Hanisch, C. (1970). The personal is political. In S. Firestone \& A. Koedt (Eds.) Notes from the Second Year, (pp. 76-78), New York: Radical Feminism

Harper, D. (2010). Tensions and dilemmas in clinical psychology's relationship with the service user movement. Clinical Psychology Forum, 209, 35-38.

Jacobson, N., \& Greenley, D. (2001). What is recovery? A conceptual model and explication. Psychiatric Services, 52, 482-485.

Laclau, E., \& Mouffe, C. (1985). Hegemony and socialist strategy: Towards a radical democratic politics. London: Verso Books

Laing, R.D. (1967). The politics of experience and the bird of paradise. Harmondsworth: Penguin

Leamy, M., Bird, V., Le Boutillier, C., Williams, J., \& Slade, M. (2011). Conceptual framework for personal recovery in mental health: Systematic review and narrative synthesis. British Journal of Psychiatry, 199, 445-452.

Lemke, T. (2001). "The birth of bio-politics": Michel Foucault's lecture at the College de France on neoliberal governmentality. Economy and Society, 30(2), 190-207.

Mirowsky, J., \& Ross, C.E. (2003) Social causes of psychological distress. Second edition Aldine de Gruyter: New York.

Ochocka, J., Nelson, G., \& Janzen, R. (2005). Moving forward: Negotiating self and external circumstances in recovery. Psychiatric Rehabilitation Journal, 28, 315-322.

O'Hagan, M. (2001). Recovery competencies for New Zealand mental health workers. Wellington: Mental Health Commission of New Zealand.

Perkins, R., \& Slade, M. (2012) Recovery in England: Transforming statutory services?, International Review of Psychiatry, 24(1), 29-39.

Pilgrim, D. (2008). "Recovery" and current mental health policy, Chronic Illness, 4, 295-304. 


\section{David Harper and Ewen Speed}

Pilgrim, D. (2009) Recovery from mental health problems: Scratching the surface without ethnography. Journal of Social Work Practice, 23, 475-487.

Ramon, S., Healy, B. \& Renouf, N. (2007). Recovery from mental illness as an emergent concept and practice in Australia and the UK. International Journal of Social Psychiatry, 53, 108122.

Roberts, A. (2008). Mental health and survivors' movements and context. Retrieved from: http:// studymore.org.uk/mpu.htm

Rogers, A., \& Pilgrim, D. (2003). Mental health and inequality. Basingstoke: Palgrave MacMillan.

Seligman, M.E.P. (1998). President's column: Building human strength: Psychology's forgotten mission. APA Monitor, January, 2.

Slade, M. (2009). 100 Ways to support recovery: A guide for mental health professionals, Rethink recovery series: volume 1. London: Rethink. Retrieved from: http://www.rethink. org/document.rm?id=8914

Smail, D. (1990). Design for a post-behaviourist clinical psychology. Clinical Psychology Forum, 28, 2-10.

Smail, D. (2004). Psychotherapy and the making of subjectivity. In P. Gordon \& R. Mayo (Eds.) Between psychotherapy and philosophy (pp. 130-140). London \& Philadelphia: Whurr.

Smail, D. (2005). Power and interest in psychology: Elements of a social materialist understanding of distress. Ross-on-Wye: PCCS.

Social Exclusion Unit. (2004). Mental health and social exclusion. London: Office of the Deputy Prime Minister.

Social Perspectives Network. (2007). Whose recovery is it anyway? London: Author. Retrieved from:http://www.spn.org.uk/fileadmin/SPN_uploads/Documents/Papers/SPN_Papers/ Recovery_and_Diversity_Booklet.pdf

Spandler, H. (2006). Asylum to action: Paddington day hospital, therapeutic communities and beyond. London: Jessica Kingsley Publishers.

Speed, E. (2006). Patients, consumers and survivors: A case study of mental health service user discourses. Social Science and Medicine, 62, 28-38.

Thornhill, H., Clare, L., \& May, R. (2004). Escape, enlightenment and endurance: Narratives of recovery from psychosis. Anthropology \& Medicine, 11, 181-199.

Topor, A., Borg, M., Di Girolamo, S., \& Davidson, L. (2011). Not just an individual journey: Social aspects of recovery. International Journal of Social Psychiatry, 57, 90-99.

Trivedi, P. (2010). A recovery approach in mental health services: Transformation, tokenism or tyranny? In T. Bassett \& T. Stickley (Eds.), Voices of experience: Narratives of mental health survivors (pp. 152-163). Chichester: Wiley.

Wallcraft, J. (2005). Recovery from mental breakdown. In J. Tew (Ed), Social perspectives in mental health: Developing social models to understand and work with mental distress. London: Jessica Kingsley.

Wallcraft, J. \& Michaelson, J. (2001). Developing a survivor discourse to replace the "psychopathology" of breakdown and crisis. In C. Newnes, G. Holmes, \& C. Dunn (Eds.), This is madness too: Critical perspectives on mental health services (pp. 177-190). Ross-onWye: PCCS Books.

White, M. (2004). Narrative practice and the unpacking of identity conclusions. In M. White, Narrative practice and exotic lives: Resurrecting diversity in everyday life (pp. 119-147). Adelaide: Dulwich Centre Publications.

Young, S.L., \& Ensing, D.S. (1999). Exploring recovery from the perspective of people with psychiatric disabilities. Psychiatric Rehabilitation Journal, 22, 219-231. 